\title{
Synthesis, characterization and bioactivity evaluation of nano-structured hydroxyapatite
}

\author{
M. H. Fathi ${ }^{1}$, V. Mortazavi ${ }^{2}$, A. Hanifi ${ }^{1}$ \& S. I. Roohani ${ }^{1}$ \\ ${ }^{1}$ Biomaterials Group, Department of Materials Engineering, \\ Isfahan University of Technology, Iran \\ ${ }^{2}$ Department of Operative Dentistry, \\ Torabinejad Dental Research Centre, School of Dentistry, \\ Isfahan University of Medical Sciences, Iran
}

\begin{abstract}
Due to its biocompatibility and bioactivity, hydroxyapatite (HA) has a wide range of applications in medical engineering cases, such as bone repair and bone tissue regeneration. The use of artificial HA with a similar structure and chemical composition to biological apatite could increase the durability of the HA inside the natural hard tissues. The aim of the present work was to synthesis nano-structured HA via different routs, the comparison of their characteristics and enhancement of the bioactivity of HA by controlling its crystallite size and chemical composition. Nano HA was prepared by mechanical activation and sol gel routs. The x-ray diffraction technique (XRD), Fourier transform infra red spectroscopy (FTIR) and transmission electron microscopy (TEM) were used to characterize the HA powder. The synthesized powder was soaked in simulated body fluid (SBF) for various periods of time in order to evaluate its bioresorbability and bioactivity after immersion in SBF. Atomic absorption spectroscopy (AAS) was used to determine the dissolution of calcium ions in the SBF media. Results showed that the prepared HA powder had a nanoscale structure with a size of $29 \mathrm{~nm}$ for the powder prepared by mechanical activation and $25 \mathrm{~nm}$ for the powder that was prepared by the sol gel method. The ionic dissolution rate of nano-structured powder was higher than conventional HA (with micro scale size) and was similar to biological apatite. It could be concluded that bioactivity behaviour of HA powder is affected by its crystallite size. Using the nano-structured HA powder with less than $50 \mathrm{~nm}$ crystallite size, the optimum bioactivity and bioresorbability would be achieved.
\end{abstract}

Keywords: nano hydroxyapatite, mechanical activation, sol gel, bioactivity. 


\section{Introduction}

Bioactive materials, such as hydroxyapatite (HA), can integrate well with living bone tissues by forming spontaneously a biologically active bone-like apatite layer on their surfaces [1-4]. HA shows excellent biocompatibility with hard skin and muscle tissues and can directly bond to the bone [5].

Mechanical activation (MA) as a solid-state reaction has been widely studied as an appropriate technique to produce nano-structured HA [6-9] and carbonate substituted HA [10-12]. Solid-state reactions usually give a stoichiometric and well-crystallized product [6-12]. Sol-gel rout, which is one of the wet chemical methods for the preparation of HA nanopowder, has a low fabrication rate but can produce products with high purity and nano-sized particles [13].

It is possible to improve the properties of HA by controlling the parameters of powder, such as particle size, distribution and agglomeration. Nano-structured HA shows suitable bioactivity. Using nano-structured HA can result in more reliable bonding with the host biological bone. Nano-structured HA powders exhibit a greater surface area and are expected to have better bioactivity than coarser crystals. Osteoconductivity, solubility, sinterability and mechanical reliability of the HA can be promoted by controlling its particle size and structural morphology in the order of nanoscale [14-17].

Biological HA contains substituted carbonate groups and presents a nanoscale structure of less than $50 \mathrm{~nm}$ in dimension. Based on these facts, artificial carbonated nano-structured HA has bioactivity, bioresorbability and biological properties, closer to biological apatite [18].

The aim of the present work was to produce nano-structured HA with less than $50 \mathrm{~nm}$ dimensions by solid state and wet chemically routs and to evaluate and compare their bioactivity with biological apatite.

\section{Experimental procedure}

The starting materials were dicalcium phosphate dihydrate $\left(\mathrm{CaHPO}_{4} \cdot 2 \mathrm{H}_{2} \mathrm{O}\right.$, Merck $>98 \%$, average size: 10 micron) and calcium carbonate $\left(\mathrm{CaCO}_{3}\right.$, Merck $>98 \%$, average size: 5 micron). Appropriate amounts of the two starting materials were mixed together at a molar ratio of 3:2. The mixture was loaded into a hardened steel bowl, together with stainless-steel balls of $20 \mathrm{~mm}$ in diameter. Mechanical activation (MA) reactions were performed in a planetary ball mill at a rotating speed of $530 \mathrm{rpm}$ and the time in the period of 2-40 hours. The mass ratio of balls to reactants was 20 , whereby the overall ball mass was $160 \mathrm{~g}$.

Sol-gel derived HA powder was prepared based on the previous study by the authors [19], and in such a manner that was previously reported [19].

The phase composition of prepared HA powders was analyzed by the x-ray diffraction (XRD) technique using $\mathrm{CuK} \alpha$ radiation generated at $40 \mathrm{kV}$ and 100 $\mathrm{mA}$, at a scan rate of $0.02 \%$. The crystallite size of the HA powders was determined by using XRD patterns and the Williamson-Hall approach [20]. Fourier transform infrared (FTIR) spectroscopy analysis (Bomem, MB 100) was 
carried out to identify the functional groups. The spectrum was recorded in the $4000-400 \mathrm{~cm}^{-1}$ region with $2 \mathrm{~cm}^{-1}$ resolution. The transmission electron microscopy (TEM) technique was utilized to evaluate the shape and size of the prepared HA powders.

In vitro bioactivity evaluation of the synthesized HA powders was performed in a simulated body fluid (SBF) media of $\mathrm{pH} 7.4$ at a ratio of $1 \mathrm{mg} / \mathrm{ml}$ in a water bath at $37^{\circ} \mathrm{C}$. The dissolution amount of calcium ions in the SBF medium were determined by atomic absorption spectrometer (AAS). The changes in the $\mathrm{pH}$ of the SBF medium were measured at pre-determined time intervals using a $\mathrm{pH}$ meter.

\section{Results and discussion}

Fig. 1 shows the XRD patterns of the powder mixtures of $\mathrm{CaHPO}_{4} \cdot 2 \mathrm{H}_{2} \mathrm{O}$ and $\mathrm{CaCO}_{3}$ that were subjected to MA for various periods of time (2-40 hours). The 2 hours milled powder showed only the $\mathrm{CaCO}_{3}$ and $\mathrm{CaHPO}_{4} \cdot 2 \mathrm{H}_{2} \mathrm{O}$ phases. By increasing the milling time, the XRD peaks became broader and the intensities decreased. The peak broadening was attributed to crystallite size refinement. This trend continued for up to 12 hours. At this stage, no peak of starting materials could be observed and according to JCPDS No. 09-0432, the only present phase was HA. Further MA led to the formation and growth of nanostructured HA. However, no additional increase in intensity was observed after 12 hours of milling, suggesting that the synthesis reaction was completed.

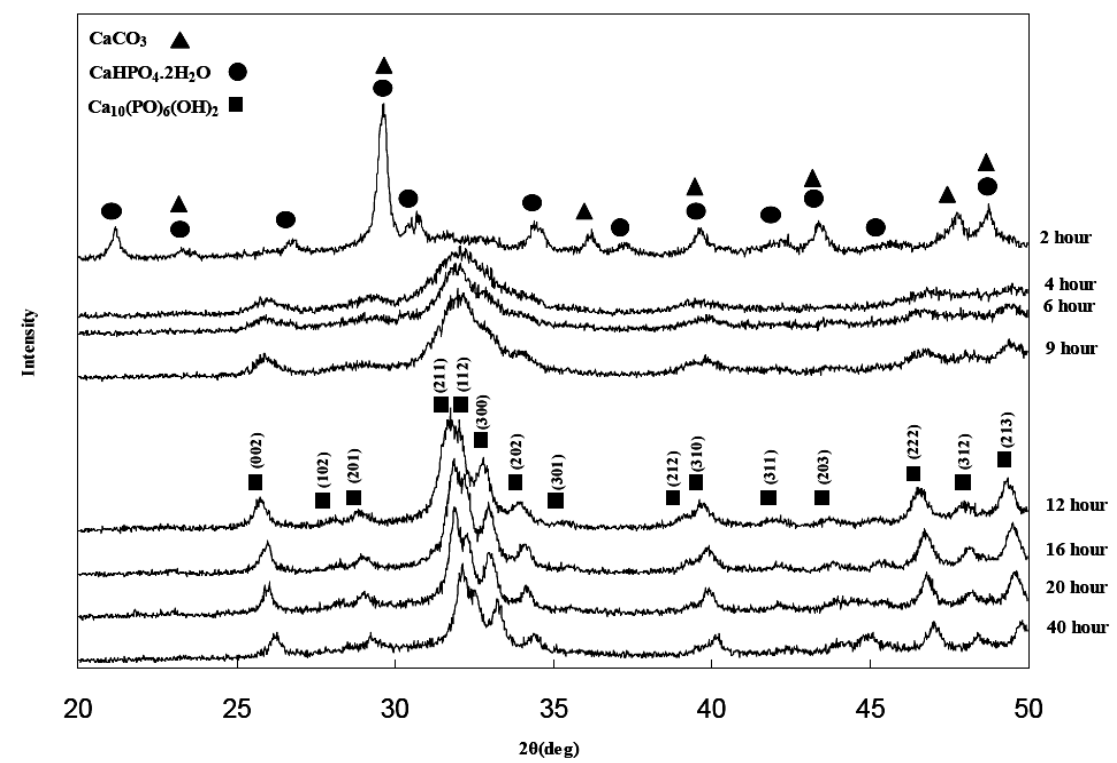

Figure 1: $\quad \mathrm{XRD}$ patterns of powder mixtures of $\mathrm{CaHPO}_{4} \cdot 2 \mathrm{H}_{2} \mathrm{O}$ and $\mathrm{CaCO}_{3}$ after ball milling for various periods of time. 


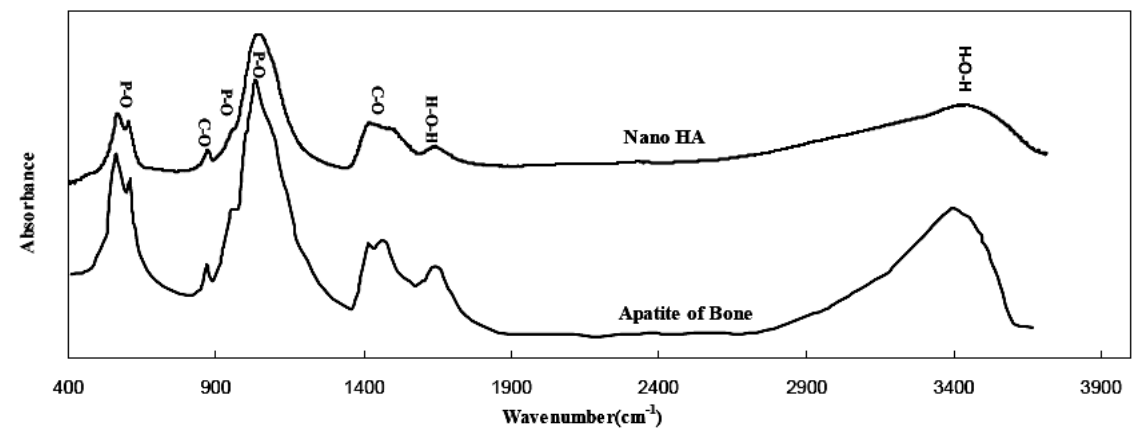

(a)

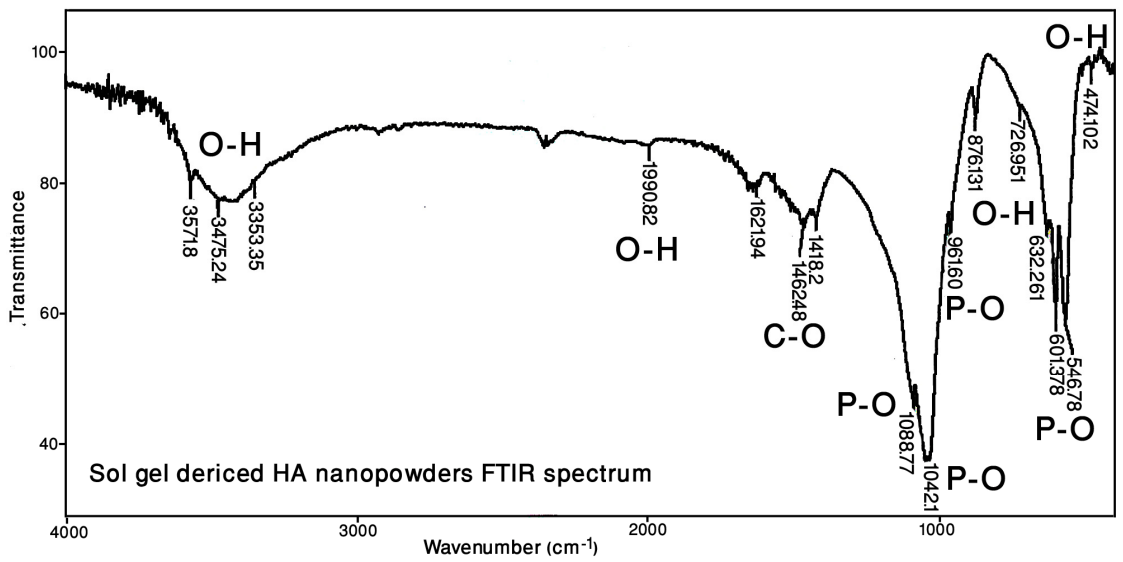

(b)

Figure 2: $\quad$ FTIR spectrum of (a) ball milled nano-structured HA and bone apatite; (b) sol-gel derived nano-structured HA.

The average crystallite size of the prepared HA after 12 hours of milling was about $29 \mathrm{~nm}$ according to the Williamson-Hall approach.

As was reported in the previous work by the authors, the XRD pattern of solgel derived HA indicated that a pure crystallite nature of typical apatite crystal structure with broad diffracted peaks could be obtained without any extraneous phases [19]. The average crystallite size of sol-gel derived HA was about $25 \mathrm{~nm}$ according to the Williamson-Hall approach. Controlling the process parameters could make the crystallite size of products in MA and sol-gel routs similar.

Fig. 2(a) shows the FTIR spectroscopy of nano-structured HA synthesized by 12 hours MA and also the biological apatite of bone. The FTIR spectrum showed all the characteristic peaks of pure HA and additionally the characteristic peak of the $\mathrm{CO}_{3}^{2-}$ group that appeared at $873 \mathrm{~cm}^{-1}, 1454 \mathrm{~cm}^{-1}$ and $1769 \mathrm{~cm}^{-1}$. Bone apatite also contains substituted carbonate ions and has a similar FTIR pattern [21]. 
The FTIR spectrum of sol-gel derived HA is also shown in Fig. 2(b), indicating all characteristic peaks of pure and stoichiometric HA. The characteristic bands from inorganic carbonate ion $\left(1465-1415 \mathrm{~cm}^{-1}\right.$ and 876 $\mathrm{cm}^{-1}$ ) are also present.

The bone contains carbonated HA having $4-6 \%$ carbonate by weight [22]. A common method for determining the type of carbonate substitution is to examine the positions of carbonate bands observed in FTIR spectra. Fig. 2 shows that carbonated HA were achieved by using both sol-gel and MA processes. As indicated earlier by Emerson and Fischer [23] and Elliott et al. [24], the place of carbonate group in FTIR spectrum in Fig. 2 is located in B type carbonated HA. In B type carbonate HA, phosphate group is replacing by carbonate groups.

Fig. 3(a) shows TEM image of 12 hours ball milled powders. The prepared HA powder has average crystallite size close to the size determined by Williamson-Hall calculation. TEM image shows high agglomerated powder with less than $50 \mathrm{~nm}$ crystallite size. Agglomeration was occurred because of high surface energy of ball milled HA powder. The morphological shape and size of sol-gel derived HA is also shown in Fig. 3(b). The sizes of the particles are in the nano scale region with a mean crystallite size of $25 \mathrm{~nm}$ in diameter. Furthermore, HA particles are not agglomerated and are mono dispersive. These differences between two types of process were shown in other studies [25, 26]. However, nano-structured powder with particle size of less than $50 \mathrm{~nm}$ could be obtained by both processes.

Results showed that nano-structured carbonated HA was produced by MA and sol-gel processes. In comparison with other researches [25-27], nanostructured HA with crystallite size less than $50 \mathrm{~nm}$ could be prepared and the solgel process that was used in this study, did not need any catalyst and $\mathrm{pH}$ control.

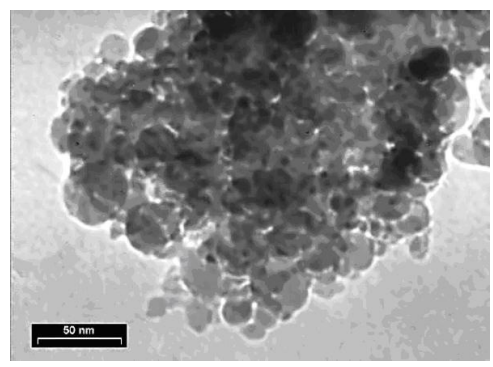

a

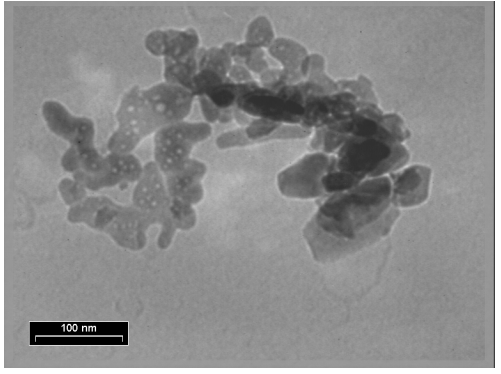

b

Figure 3: $\quad$ TEM micrograph of nano-structured HA powder produced by; (a) MA; and (b) sol-gel processes.

Fig. 4 (a) shows the trend of releasing of calcium ions from nano-structured $\mathrm{HA}$ into SBF. More calcium ions were released from the nano-structured HA as compared with conventional HA (Con. HA). The amount of calcium release from the nano-structured HA corroborated well with the calcium release pattern of biological apatite [28]. The ionic dissolution rate of ball milled nano- 


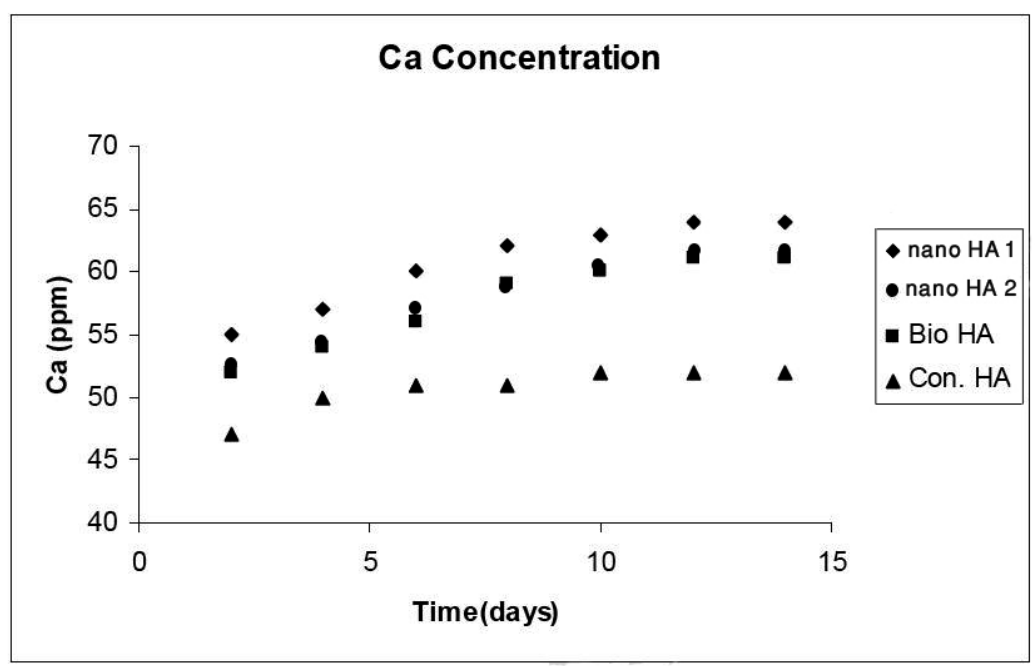

(a)

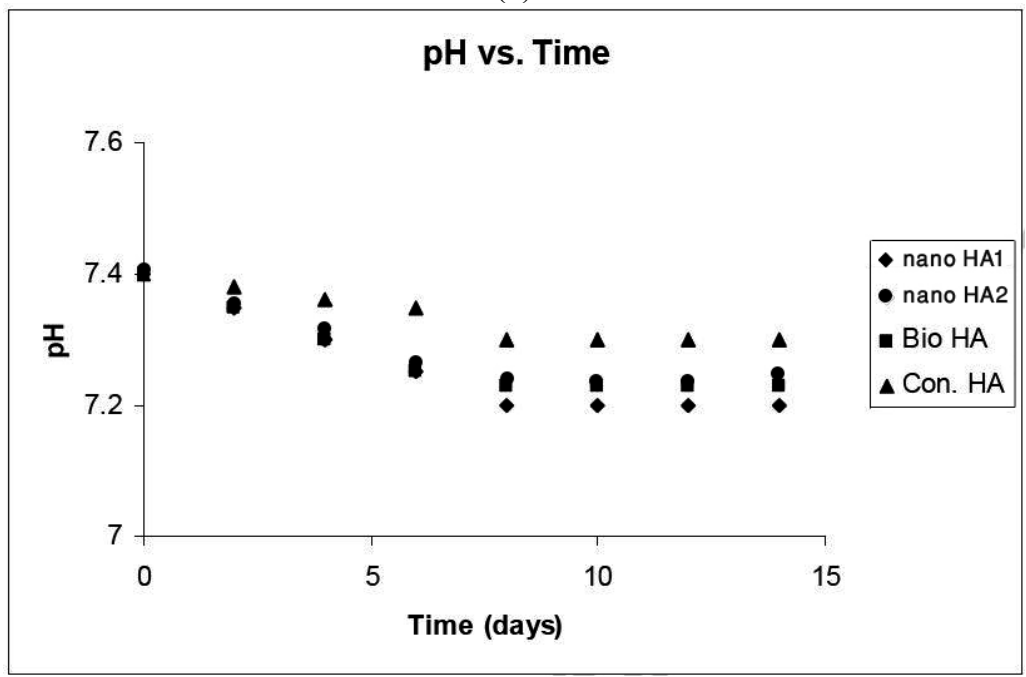

(b)

Figure 4: (a) Release of calcium ions from sol-gel derived nano-structured HA (nano HA1), ball milled nano-structured HA (nano HA2), biological HA (Bio HA) and conventional HA (Con. HA). (b) The changes of $\mathrm{pH}$ versus time for nano HA1, nano HA2, Bio HA, and Con. HA.

structured HA (nano HA 2) is much similar to that of sol-gel derived nanostructured HA (nano HA 1) and biological HA (Bio. HA). As the solubility is highly sensitive to the structural and chemical compositions of the apatite, the crystallite size is an essential key factor for in vitro behaviour of HA. 
There is a little difference between the ionic dissolution rate of nano HA 1 and nano HA 2. This is because of agglomeration of ball milled powder. Surface area is one of the most effective factors on ion releasing. Sol-gel derived HA contains nano scale individual particles that make its surface area higher than ball milled HA.

Fig. 4 (b) shows a graph of the changes of $\mathrm{pH}$ versus time which illustrates the resorbability of nano HA 1 and nano HA 2. The graph also shows the variation of $\mathrm{pH}$ versus time for a Con. HA and, Bio. HA for comparison. The $\mathrm{pH}$ changes of the Con. HA were found to be insignificant variation trend as it was not resorbed in SBF medium which indicates its physiological stability during the period of study. The nano HA 1 showed drastic $\mathrm{pH}$ changes, suggesting that it dissolves much faster than Con. HA. The $\mathrm{pH}$ value depends on solubility or resorbability of the HA. As the $\mathrm{pH}$ decreases, the solubility increases. Accordingly, it is clear from the Fig. 4 (b) that the rate of bioresorbability of the prepared nano-structured HA is higher than the rate of bioresorbability of the Con. HA and is similar to Bio. HA.

Based on the type of medical application, bioactivity of the HA can be controlled by its crystallite size. Due to the presence of substituted carbonate groups and nanoscale structure, prepared HA powder shows the similar bioactivity and bioresorbability properties to biological apatite and could be used near the hard tissues [29-31]. Using such as nano-structured HA can improve the host/implant reactions in biomedical applications.

\section{Conclusion}

Carbonated nano-structured HA with crystallite size less than $50 \mathrm{~nm}$ was prepared by mechanical activation and sol-gel processes. Prepared carbonated nano-structured HA showed similar bioactivity properties to biological apatite. Bioactivity of nano-structured HA was affected by its crystallite size and was independent to the type of preparing routs. Controlling the crystallite size of HA is the most effective factor on bioactivity behaviour.

\section{References}

[1] Kokubo, T., Kim, H.M. \& Kawashita, M., Novel bioactive materials with different mechanical properties, Biomaterials, 24, pp. 2161-2175, 2003.

[2] Siriphannon, P., Kameshima, Y., Yasumori, A., Okada, K. \& Hayashi, S., Formation of hydroxyapatite on $\mathrm{CaSiO} 3$ powders in simulated body fluid, J. Eur. Ceram Soc, 22, pp. 511-520, 2002.

[3] Oyane, A., Onuma, K., Ito, A., Kim, H.M., Kokubo \& Nakamura, T., Formation and growth of clusters in conventional and new kinds of simulated body fluids, J. Biomed. Mater. Res, 64, pp. 339-348, 2003.

[4] Leng, Y., Chen, J.Y. \& Qu, S.X., TEM Examinations of Calcium Phosphate Precipitation on HA/TCP, Biomaterials, 24, pp. 2125-2131, 2003. 
[5] Fathi, M.H. \& Azam, F., Novel hydroxyapatite/tantalum surface coating for metallic dental implant, Mater. Lett, 61, pp. 1238-1241, 2007.

[6] Kim, W. \& Saito, F., Mechanochemical Synthesis of Hydroxyapatite from Constituent Powder Mixtures by Dry Grinding, J. Chem. Eng. Jpn, 33, pp. 768-772, 2000.

[7] Yeong, B., Juamin, X. \& Wang, J.J., Mechanochemical synthesis of hydroxyapatite from calcium oxide and brushite, J. Am. Ceram. Soc, 84, pp. 465-467, 2000.

[8] Kim, W., Zhang, Q. \& Saito, F., Mechanochemical synthesis of hydroxyapatite from $\mathrm{Ca}(\mathrm{OH}) 2-\mathrm{P} 2 \mathrm{O} 5$ and $\mathrm{CaO}-\mathrm{Ca}(\mathrm{OH}) 2-\mathrm{P} 2 \mathrm{O} 5$ mixtures, J. Mater. Sci, 35, pp. 5401-5405, 2000.

[9] Silva, C.C., Pinheiro, A.G. \& Miranda, A.M.R., Structure properties of hydroxyapatite obtained by mechanosynthesis, Solid State Sci, 5, pp. 553$558,2003$.

[10] Suchanek, W.L., Shuk, P., Byrappa, K., Riman, R.E., Ten Huisen, K.S. \& Janas, V.F., Mechanochemical-hydrothermal synthesis of carbonated apatite powders at room temperature, Biomaterials, 23, pp. 699-710, 2002.

[11] Riman, R.E., Suchanek, W.L., Byrappa, K., Chena, C.W., Shuka, P. \& Oakesa, C.S., Solution synthesis of hydroxyapatite designer particulates, Solid State Ionic, 151, pp. 393-402, 2002.

[12] Rhee, S.H., Synthesis of hydroxyapatite via mechanochemical treatment, Biomaterials, 23, pp. 1147-1152, 2002.

[13] Liu, D. M., Troczynski, T. \& Tseng, W.J., Water-based sol-gel synthesis of hydroxyapatite: process development, Biomaterials, 22, pp. 1721-1730, 2001.

[14] Stupp, S.I. \& Ciegler, G.W., Organoapatites: materials for artificial bone. I. Synthesis and microstructure, J. Biomed. Mater. Res, 26, pp. 169-183, 1992.

[15] Webster, T.J., Siegel, R.W. \& Bizios, R., Enhanced. osteoclast-like cell functions on nanophase ceramics, Biomaterials, 22, pp. 1327-1333, 2001.

[16] Vasconcelos, I.F., Optical properties of Bi12SiO20 (BSO) and Bi12TiO20 (BTO) obtained by mechanical alloying, J. Mat. Sci., 36, pp. 578-592, 2001.

[17] Murugan, R., Rao, K.P. \& Kumar, T.S.S., Heat-deproteinated xenogeneic bone from slaughterhouse waste: physico-chemical properties, Bull. Mater. Sci., 26, pp. 523-528, 2003.

[18] Silva, G.A., Introduction to Nanotechnology and Its Applications to Medicine, Elsevier Inc., 2004.

[19] Fathi, M.H. \& Hanifi, A., Evaluation and characterization of nanostructure hydroxyapatite powder prepared by simple sol-gel method, Mater. Lett., 61, pp. 3978-3983, 2007.

[20] Williamson, G.K. \& Hall, W. H., X-ray line broadening from filed. aluminium and wolfram, ActaMetall., 1, pp. 22-31, 1953.

[21] Kokubo, T. \& Takadama, H., How useful is SBF in predicting in vivo bone bioactivity, Biomaterials, 27, pp. 2907-2915, 2006. 
[22] Sinha, A., Ingle, A., Munim, K.R., Vaidya, S.N., Sharma, B.P. \& Bhisey, A.N., Development of calcium phosphate-based bioceramics, Bull. Mater. Sci., 24, pp. 653-657, 2001.

[23] Emerson, W.H. \& Fischer, E.F., The infrared absorption spectra of carbonate in calcified tissues, Arch. Oral. Biol., 7, pp. 671-687, 1962.

[24] Elliott, J.C., Holcom, D. W. \& Young, R.A., Infrared determination of the degree of carbonate ions in human dental enamel, Calcif. Tissue. Int., 37, pp. 372-375, 1985.

[25] Comby, S., Gumy, F., Bünzli, G., Saraidarov, T. \& Reisfeld, R., Luminescent properties of an $\mathrm{Yb}$ podate in sol-gel silica films solution, and solid state, Chem. Phys. Lett., 432, pp. 128-132, 2006.

[26] Kalita, S. J., Bhardwaj, A. \& Bhatt, H.A., Nanocrystalline calcium phosphate ceramics in biomedical engineering, Mater. Sci. Eng. C., 27, pp. 441-449, 2007.

[27] Banerjee, A., Bandyopadhyay, A. \& Bose, S., Hydroxyapatite nanopowders: synthesis, densification and cell-materials interaction, Mater. Sci. Eng. C, 27, pp. 729-735, 2007.

[28] Muragan, R. \& Ramakrishna, S., Aqueous mediated synthesis of biore -. sorbable nanocrystalline hydroxyapatite, J. Cryst. Growth, 274, pp. 209213, 2005.

[29] Webster, T.J., Siegel, R.W. \& Biozios, R., Enhanced surface and mechanical properties of nanophase ceramics to achieve orthopaedic/dental implant efficacy, Key. Eng. Mater., 192, pp. 321-324, 2001.

[30] Webster, T.J., Ergun, C., Doremus, R.H., Siegel, R.W. \& Biozios, R., Enhanced functions of osteoblasts on nanophase ceramics, Biomaterials, 21, pp. 1803, 2000.

[31] Webster, T.J., Specific proteins mediate enhanced osteoblast adhesion on nanophase ceramics, J. Biomed. Mater. Res., 51, pp. 475-483, 2000. 